\title{
Heat shock protein 27 and glycogen phosphorylase isoenzyme BB as markers of myocardial stunning in male water polo players.
}

\author{
Snezana Pantovic*, Vjeroslava Slavic, Milovan Roganovic \\ University of Montenegro, Krusevac bb, Podgorica, Montenegro
}

\begin{abstract}
Introduction: Sudden cardiac death has a tendency to increase among elite athletes. It has been reported that endurance exercise increased serum concentrations of cardiac biomarkers in elite athletes although it is unclear whether is clinically significant or is a part of the physiological response. Lately, the theory of myocardial stunning is attractive since there is no permanent cellular damage and is transient nature. This prompts us to evaluate the significance of Hsp27 and GP-BB as sensitive and specific biomarkers of myocardial stunning in elite male water polo players.

Materials and methods: A prospective and experimental study included 20 elite male water polo players, randomly divided into two groups that matched for age, length of active practicing water polo and level of physical stamina. Blood samples for testing were obtained at the following time points: baseline, 1, 30 and $60 \mathrm{~min}$ following exercise as well as for control group.

Results: Endurance exercise has resulted in an increased serum concentration of $\mathrm{Hsp} 27$ at $50 \%$ after 1, $60 \%$ after 30 and $80 \%$ of water polo players after $60 \mathrm{~min}$. Simultaneously, serum concentration of GPBB were increased in $40 \%$ of water polo players after $1 \mathrm{~min}$ as well as for $10 \%$ after 30 and $60 \mathrm{~min}$. Further analysis has established significantly positive correlations among obtained serum concentration of Hsp27 and GP-BB at $1(p<0.05)$ and $30(p<0.01)$ min.

Conclusion: Serum concentration of Hsp27 could be important indicator of the risk assessment and prevention of developing heart damage in water polo players or for athletes in general. Positive correlation between Hsp27 and GP-BB indicating the reversibility damages of structural and contractile proteins in myocardial cells. Further investigation is needed to investigate connection to oxidative stress as a significant part of metabolic exhaustion of myocardial cells.
\end{abstract}

Keywords: GP-BB, Hsp27, Myocardial stress.

Accepted on July 20, 2018

\section{Introduction}

Endurance exercise is associated with transient elevations of heat shock proteins (Hsp) expression, body temperature, hormones, and oxidative stress [1]. The effect of prolonged exercise on cardiac muscle integrity and function is less well known [2]. At present, the risk of myocardial damage by endurance exercise is under debate because of reports on exercise-associated increases in cardiac biomarkers which are typically elevated in patients with acute myocardial infarction and chronic heart failure [3]. Emerging evidence suggests that prolonged exercise may be associated with cardiac fatigue or cardiac damage, although the clinical implications remain obscure [4]. So, the theory of stunning is attractive on the basis that it does not result in necrosis and permanent cellular damage and is transient in nature [2].

Hsp play critical roles in body self-defence under a variety of stresses, including endurance exercise, through regulation of folding and functions of relevant cellular proteins [5]. These ubiquitous and conserved proteins can be found inside and outside the cell [6]. Although initially characterized as intracellular chaperones, subsequent studies pointed to the presence of Hsp in the extracellular space [7,8]. Extracellular Hsp have consequently been ascribed novel functions (such as outside-in signalling), expanding their canonical role of maintaining homeostasis in the cell to that of the whole organism [9].

Hsp27 is a member of a small Hsp family, $27 \mathrm{kDa}$ molecular weight, highly specific for cardiovascular cells such as cardiomyocytes and endothelial cells [10]. Intracellular Hsp27 maintains cellular homeostasis through involvement in cytoskeletal architecture and dynamics [11,12]. So, it has been demonstrated that over-expression of Hsp27 can protect the integrity of the microtubules and the actin cytoskeleton in cardiac myocytes and endothelial cells exposed to ischemia $[13,14]$. Also, Hsp27 can be secreted outside the cell and can be found in a soluble form in the circulation. Its extracellular concentration is proportional to its intracellular concentration [15]. Recently indicated that extracellular concentration of Hsp27 are implicate in the regeneration of endothelial barrier 
[16]. According to literature Hsp27 is a part of protective mechanism through its over-expression even in the absence of other protective procedures [17].

Endurance exercise is associated with transient cellular damage of cardiomyocytes as we mentioned before. Our assumption is that this is a metabolic exhaustion of myocardial cells. In recent years, special attention has been drawn to glycogen phosphorylase isoenzyme BB (GP-BB) as a specific serum marker of myocardial ischemia [18]. GP-BB is released from cardiac cells during myocyte damage [19]. Moreover, human studies suggest a higher sensitivity of GP-BB compared to other cardiac markers. GP-BB is not dependent on cellular death and necrosis for release, and thus is a true marker of ischemia [20].

Subject of our interest is water polo sport as the oldest continuous Olympic team sport. Water polo is a physically demanding sport; action is continuous, and players commonly swim three kilometres or more during four periods of play [21-23]. Water polo is a sport involving extremely intense exercise training that might be expected to result in major cardiac adaptations. Therefore, in this study we examined if this extremely strenuous sport was hazardous to cardiovascular health of young male water polo players.

\section{Materials and Methods}

Total of 20 elite male water polo players, members of junior national team of Montenegro, was studied. They were randomly divided in two groups: the first group was exposed to a strenuous exercise (exercise group; $n=10$ ) and the second group served as control (non-exercise group; $n=10$ ). The groups were matched for age, levels of physical stamina, length of active practicing water polo and trained under identical condition. Strenuous training lasted $1 \mathrm{~h}$ in the pool at a temperature of $26^{\circ} \mathrm{C}$, in accordance with the Protocol by FINA. Training consisted of four phases: (1) aerobic-1500 m easy pace in $50 \mathrm{~m}$ shares with short breaks by $10 \mathrm{~s}$; (2) aerobicanaerobic- $800 \mathrm{~m}$ faster pace in $200 \mathrm{~m}$ shares with $30 \mathrm{~s}$ breaks; (3) anaerobic-lactic- $200 \mathrm{~m}$ maximum speed in sections of 50 $\mathrm{m}$, with pauses that lasted twice as long as the time required for swimming across stocks; (4) anaerobic-lactate-100 m maximum speed in sections of $25 \mathrm{~m}$ with pauses that lasted at least twice as long as the time required for swimming across stocks. Blood samples were obtained at the following time points: baseline (before training), 1, 30 and 60 min following the exercise (same in non-exercise group). Serum was collected and stored in triplicate (at least $0.5 \mathrm{ml}$ ) aliquots with appropriate labelling and then were frozen (less than $25^{\circ} \mathrm{C}$ ). Concentrations of Hsp27 and GP-BB were determined in duplicate by ELISA (Calbiochem, USA for Hsp27, referent values $0.02-1 \mathrm{ng} / \mathrm{ml}$; Diagenics, USA for GP-BB, referent values $0.6-4 \mu \mathrm{g} / \mathrm{L}$ ). At the same time points blood pressure and heart rate were measured. Study was approved by Ethical Committee of Faculty of Medicine, University of Nis, Serbia.

Obtained results were statistically analysed using SPSS 15.0 statistical software. Statistical analyses included paired t-test and Pearson correlation as appropriate. A p value $<0.05$ was considered statistically significant.

\section{Results}

Two analysed groups, exercise and non-exercise, were matched in relation to age, body weight, body height, body mass index and length of years in water polo sport.

All analysed water polo players had increased serum concentration of Hsp27 basal/before exercise. Strenuous exercise induced a significant increase Hsp27 concentration immediately after strenuous exercise, precisely $1 \mathrm{~min}$ after $(t=6.735 ; p<0.001)$ in comparison to their concentration before exercise (Figure 1).

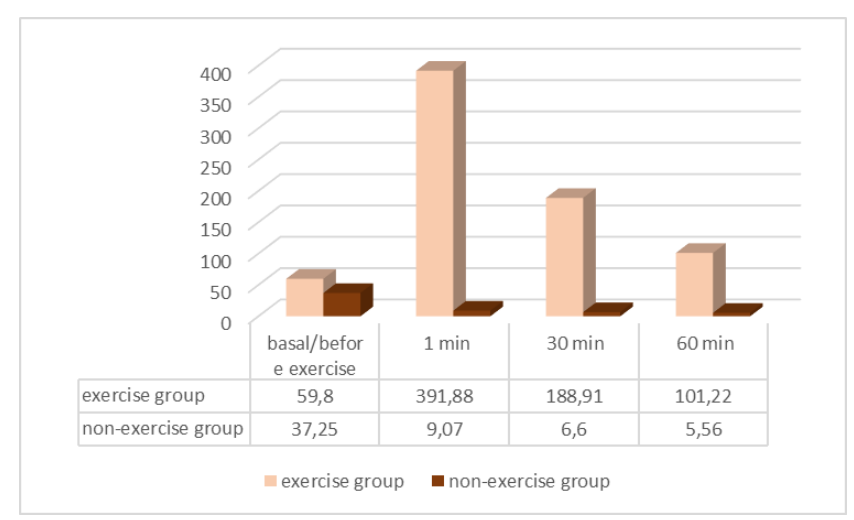

Figure 1. The average concentration of Hsp27 (ng/ml) in water polo players basal/before exercise, 1, 30 and $60 \mathrm{~min}$ following exercise.

Upon reaching the peak, the Hsp 27 concentration decreases during 30 and 60 min after exercise. Obtained concentrations following exercise 1 and $30 \mathrm{~min}$ exercise were in significantly positive correlation $(\mathrm{r}=0.992 ; \mathrm{p}<0.01)$ as well as following 30 and $60 \min (\mathrm{r}=0.994 ; \mathrm{p}<0.01)$.

Serum concentrations of GP-BB were in the reference range in all water polo players. Strenuous exercise induced significantly increased concentration $1 \mathrm{~min}$ following exercise $(\mathrm{t}=3.205$; $\mathrm{p}<0.011$ ) (Figure 2).

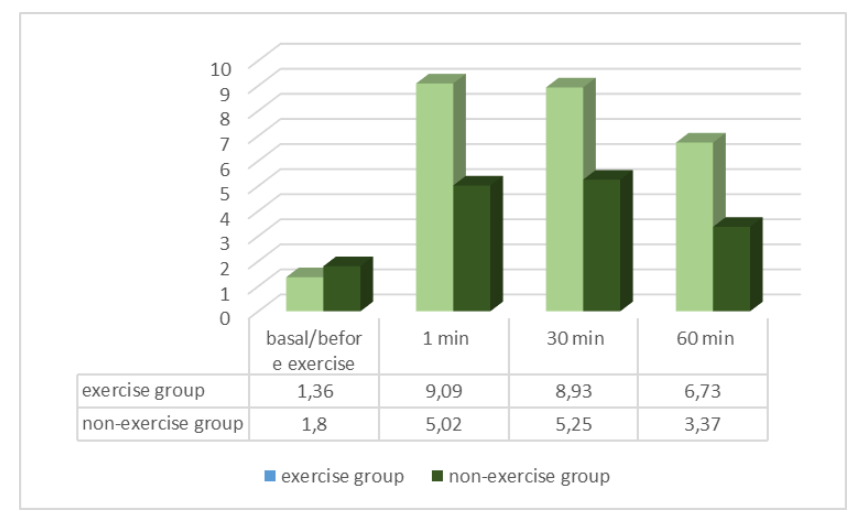

Figure 2. Mean concentration of $G P-B B(\mu g / L)$ in water polo players basal/before exercise, 1, 30 and $60 \mathrm{~min}$ following exercise.

Increased concentrations are maintained at the same rate in the next $30 \mathrm{~min}$ and were in significantly positive correlation 
$(\mathrm{r}=0.895 ; \mathrm{p}<0.001)$. Further, the concentration of GP-BB decline to $60 \mathrm{~min}$ but remain in significantly positive correlation with obtained concentration for $30 \mathrm{~min}(\mathrm{r}=0.697$; $\mathrm{p}<0.03)$.

Although serum concentration of GP-BB were higher in exercise compare to non-exercise group, statistically significant difference were only for concentrations obtained for 60 min following exercise $(\mathrm{t}=2.677 ; \mathrm{p}<0.025)$.

Additionally, serum concentrations of Hsp27 and GP-BB were in significant positive correlation in $1(\mathrm{r}=0.716$; $\mathrm{p}<0.05)$ and 30 $\min (r=0.776 ; p<0.01)$ following exercise.

Mutual these two groups of analysed water polo players did not differ in mean value of diastolic and systolic blood pressure as well as heart rate frequency basal/before training.

In the first minute after exercise the exercise group had significantly higher values of the SBP $(\mathrm{t}=12.784, \mathrm{p}<0.001)$, DBP $(\mathrm{t}=8.947, \mathrm{p}<0.001)$, and HR $(\mathrm{t}=10.690, \mathrm{p}<0.001)$ compared to the non-exercise group (Table 1). The differences between the thirtieth and sixtieth minutes were not statistically significant.

We also analysed whether there was a connection between Hsp27 and GP-BB concentration to the values of blood pressure and heart rate frequency. Our results indicate only a significant negative correlation to the systolic pressure for Hsp27 concentrations $30 \quad(\mathrm{r}=-0.726 ; \mathrm{p}<0.05)$ and $60 \mathrm{~min}$ $(\mathrm{r}=-0.706 ; \mathrm{p}<0.05)$; for GP-BB concentrations $1(\mathrm{r}=-0.696$, $\mathrm{p}<0.05)$ and $30 \min (r=-0.644, \mathrm{p}<0.05)$ following exercise.

Table 1. Variation of mean values of blood pressures, systolic and diastolic, and heart rate frequencies at following time points.

\begin{tabular}{|c|c|c|c|c|c|c|c|c|}
\hline \multicolumn{2}{|c|}{ Values } & \multicolumn{3}{|c|}{ Exercise group } & \multicolumn{3}{|c|}{ Non-exercise group } & \multirow[t]{2}{*}{$\mathbf{p}$} \\
\hline & & $\mathbf{X}_{\min }-\mathbf{X}_{\max }$ & $\mathbf{x}_{\mathrm{m}}$ & SD & $\mathbf{X}_{\min }-\mathbf{X}_{\max }$ & $\mathbf{x}_{\mathrm{m}}$ & SD & \\
\hline \multirow[t]{3}{*}{ SBP } & $1 \mathrm{~min}$ & $135-150$ & 114.5 & 4.97 & $110-122$ & 114.7 & 5.25 & $<0.001$ \\
\hline & $30 \mathrm{~min}$ & $105-130$ & 142.5 & 6.35 & $105-120$ & $\begin{array}{l}113.0 \\
4\end{array}$ & 4.83 & ns \\
\hline & $60 \mathrm{~min}$ & $100-120$ & 112 & 5.87 & $100-120$ & 113 & 6.32 & ns \\
\hline \multirow[t]{3}{*}{ DBP } & $1 \mathrm{~min}$ & $80-100$ & 89 & 8.1 & $60-75$ & 68.5 & 4.12 & $<0.001$ \\
\hline & $30 \mathrm{~min}$ & $70-85$ & 75.5 & 5.5 & $60-70$ & 66.5 & 4.12 & ns \\
\hline & $60 \min$ & $60-80$ & 70 & 6.67 & $60-70$ & 66 & 3.94 & ns \\
\hline \multirow[t]{3}{*}{ HR } & $1 \mathrm{~min}$ & $113-147$ & 132.3 & 10.91 & $62-98$ & 74.7 & 9.93 & $<0.001$ \\
\hline & $30 \mathrm{~min}$ & $70-82$ & 76.7 & 3.5 & $60-95$ & 73.9 & 8.82 & ns \\
\hline & $60 \mathrm{~min}$ & $66-70$ & 69.2 & 1.4 & $58-94$ & 73.8 & 9.35 & ns \\
\hline
\end{tabular}

\section{Discussion}

The question whether endurance exercise is associated with structural or functional damage of the human heart is of utmost importance for physicians involved in the medical care and guidance of endurance athletes. If myocardial damage occurs with prolonged exercise, this would result in the release of myocardial cellular proteins into the general circulation, where it can be detected [24]. Recent studies, particularly emphasize the importance of the process labelled as myocardial stunning caused by ischemia or coronary vasospasm [25] which is transient in nature and does not result in necrosis and permanent cellular damage [2].

It is now well established that prolonged exercise results in an increase in expression of stress proteins in many organs including cardiac muscle [25]. Intensive and regular exercise results in increased basal Hsp concentration which is directly dependent on the intensity, duration and type of exercise. The increase in basal Hsp concentration suggests that this protective system is functional in maintaining cytoskeletal structures, redox potential and accelerating the biogenesis of mitochondria [26]. According to the literature all analysed water polo players had increased serum concentrations of Hsp27 basal/before exercise as a part of preconditioning through regular training program.

Importantly, evidence also exists to suggest that exercise induction of stress proteins can provide myocardial protection [27]. So, Hsp 27 has been shown to occur in relatively high concentrations in heart tissue $[25,26]$ as intracellular protein. Also, the presence of Hsp27 has been detected in human serum, with elevations observed after extreme exercise [28,29]. Secretion of Hsp27 from cells can occur independent of cell death due to increased permeability of cell membranes [30]. Indeed, immediately after exercise obtained significantly increase serum concentrations of Hsp27 in water polo players in comparison to the concentrations before exercise.

According to published studies, GP-BB was highly specific and highly sensitive marker of early myocardial ischemia indicating ischemic minimal myocardial damage at an early stage [31]. Its release in circulation requires both, burst of glycogenolisis and concomitantly increased plasma membrane permeability [32]. GP-BB concentration increases immediately after strenuous exercise like $21 \mathrm{~km}$ run, cross country running or cycling $[29,33]$. In accordance with the literature, water polo players had significantly increased serum concentration of GP$\mathrm{BB}$ in the first minute after strenuous training.

Strenuous exercise consists of aerobic and anaerobic phases and that including lactate and lactate phases. This means that induces intense metabolic stress of myocardial cells. Osbakken and Locko employed stress-redistributed thallium scans and reported possible evidence of myocardial perfusion defects in trained athletes after $40 \pm 7$ min of fatigue limited sub maximal bicycle exercise [34]. This perfusion defects are the basis for the generation of minimal myocardial damage or disruption of endothelial barrier. Our results indicate this myocardial damage through increasing GP-BB concentrations at the first minute following exercise as a marker of early ischemia or vasospasm. Transient nature of this damages or vasospasm is confirmed by decreasing its concentration in 30 and 60 min after finishing strenuous exercise. Meanwhile, increased serum concentration of Hsp27 immediately after exercise point on disrupted endothelial barrier. In the next 30 and $60 \mathrm{~min}$, the concentration is reduced in order to restore the functional 
endothelial barrier. Additionally, serum concentrations of Hsp27 as cardioprotective marker significantly positively correlated between the measurement intervals. Moreover, serum concentration of Hsp27 as cardioprotective marker and GP-BB as an early marker of ischemia were in significant positive correlation 1 and $30 \mathrm{~min}$ following training.

Concerning the structure of water polo players motion during game, $35 \%$ of overall time the players is in quasi-horizontal phase (all swimming at all levels of intensity during game), whereas the remaining $65 \%$ of the time in quasi-vertical phase (vertical position achieved by leg work known as water polo cycling) [35]. Myocardial blood flow is stopped or greatly reduced during systole based on contractile force so that during exercise coronary perfusion in diastole increases due to a dramatically increased intravascular pressure [36]. So, endurance exercise induced significantly higher values of SBP, DBP and HR in water polo players immediately after, more precisely in the first minute. GP-BB concentrations were in significant negative correlation to SBP in 1 and $30 \mathrm{~min}$ after exercise, in period of existing myocardial perfusion defects. Concurrently, Hsp27 is a powerful cytoprotective protein responsible for maintaining myocardial cytoskeletal conformation and cellular homeostasis, thereby enhancing cell survival ability in ischemia [27]. In the absence of hypoxia, they act as molecular chaperons with a significant role in normal myocardial cell function. So, in the period of recovery and establishment of normal coronary perfusion following strenuous exercise, 30 and $60 \mathrm{~min}$, Hsp27 concentration were in significant negative correlation only to SBP.

In summary, serum Hsp27 could be important indicators of the risk assessment and prevention of developing heart damage in water polo players or for athletes in general. Positive correlation between Hsp27 and GP-BB indicating the reversibility damages of structural and contractile proteins in myocardial cells. Further investigations are needed to investigate connection to oxidative stress as a significant part of metabolic excretion of myocardial cells.

\section{Acknowledgements}

No acknowledgements.

\section{References}

1. Locke M, Noble EG, Atkinson BG. Exercising mammals synthesize stress proteins. Am J Physiol 1990; 258: C723-729.

2. Dawson E, George K, Shave R, Whyte G, Ball D. Does the human heart fatigue subsequent to prolonged exercie? Sports Med 2003; 35: 365-380.

3. Scharhag J, George K, Shave R, Urhausen A, Kindermann W. Exercise-associated increases in cardiac biomarkers. Med Sci Sports Exerc 2008; 40: 1408-1415.

4. Green DJ, Naylor LH, George K. Cardiac and vascular adaptations to exercise. Curr Opin Clin Nutr Metab Care 2006; 9: 677-684.
5. Noble EG, Shen XG. Impact of exercise and metaobolic disorders of heat shock proteins and vascular inflammation. Autoimmune Dis 2012; 83: 651-659.

6. Moseley PL. Heat shock proteins and the inflammatory response. Ann N Y Acad Sci 1998; 856: 206-213.

7. De Maio A, Vazquez D. Extracellular heat shock proteins: a new location, a new function. Shock 2013; 40: 239-246.

8. Calderwood SK. Heat shock proteins in extracellular signaling. Methods 2007; 43: 167.

9. Batula Z, Venu VKP, Li Y, Koumbadinga G, AlvarezOlmedo DG, Shi C. Extracellular release and signaling by heat shock protein 27: Role in modifying vascular inflammation. Front Immunol 2016; 7: 285-300.

10. Benjamin IJ, McMillan DR. Stress (heat shock) proteins. Molecular chaperones in cardiovascular biology and diseases. Circ Res 1998; 83: 117-132.

11. Huot J, Houle F, Spitz D.R, Landry J. HSP27 phosphorylation-mediated resistance against actin fragmentation and cell death induced by oxidative stress. Cancer Res 1996; 56: 273-279.

12. Mounier N, Arrigo AP. Actin cytoskeleton and small heat shock proteins: how do they interact? Cell Stress Chaperones 2002; 7: 167-176.

13. Bluhm WF, Martin JL, Mestril R, Dillmann WH. Specific heat shock proteins protect microtubules during simulated ischemia in cardiac myocytes. Am J Physiol 1998; 275: H2243-2249.

14. Loktinova SA, Ilynskaya OP, Kabakov AE. Early and delayed tolerance to stimulated ischemia in hetpreconditioned endothelial cells: a role for HSP27. Am J Physiol 1998; 392: 821-824.

15. $\mathrm{Xu} \mathrm{Q}$. Role of heat shock proteins in atherosclerosis. Arterioscler Thromb Vasc Biol 2002; 22: 1547-1559.

16. Ma X, Hibbert B, McNulty M, Hu T, Zhao X, Ramirez FD, Trevor S, Jacqueline S. de B, Edward RO. Heat shock protein 27 attenuates neointima formation and accelerates reendothelialization after arterial injury and stent implantation: importance of vascular endothelial growth factor up-regulation. FASEB J 2014; 28: 594-602.

17. Latchman DS. Heat shock proteins and cardiac protection. Cardiovasc Res 2001; 51: 637-646.

18. Apple FS, Wu AH, Mair J, Ravkilde J, Panteghini M, Tate J, Pagani F, Christenson RH, Mockel M, Danne O, Jaffe AS, Committee on Standardization of Markers of Cardiac Damage of the IFCC. Future biomarkers for detection of ischemia and risk stratification in acute coronary syndrome. Clin Chem 2005; 51: 810-824.

19. Dobric M, Giga V, Beleslin B, Ignjatovic S, Paunovic I, Stepanovic J, Djordjevic-Dikic A, Kostic J, Nedeljkovic I, Nedeljkovic M, Tesic M, Dajak M, Ostojic M. Glycogen phosphorylaseisoenzyme BB plasma kinetics is not related to myocardial ischemia induced by exercise stree echo test. Clin Chem 2013; 51: 2029-2035.

20. Kemp M, Donovan J, Higham H, Hooper J. Biochemical markers of myocardial injury. Br J Anaesth 2004; 93: 63-73. 
21. Barr DA. Guide to Water polo. Sterling Publishing (London) 2001; 23-25.

22. Smith HK. Applied physiology of water polo. Sports Med 1998; 26: 317-334.

23. Marion A, Honish A. Coache's infoservice, sports science information for coaches: Water Polo Shot 2006.

24. Starnes JW, Bowles DK. Role of exercise in the cause and prevention of cardiac dysfunction. Exerc Sport Sci Rev 1995; 23: 349-373.

25. Locke M. The cellular stress response to exercise: role of stress proteins. Exerc Sport Sci Rev 1997; 25: 105-136.

26. Lippi G, Schena F, Montagnana M, Salvagno GL, Guidi GC. Influence of acute physical exercise on emerging muscular bomarkers. Clin Chem Lab Med 2008; 46: 1313-1318.

27. Powers SK, Locke M, Demirel HA. Exercise, heat shock proteins, and myocardial protection from I-R injury. Med Sci Sports Exerc 2001; 33: 386-392.

28. Lancaster GI, Febbraio MA. Mechanisms of stressinduced cellular HSP72 release: implications for exerciseinduced increases in extracellular HSP72. Exerc Immunol Rev 2005; 11: 46-52.

29. Lancaster GI, Moller K, Nielsen B, Secher NH, Febbraio MA, Nybo L. Exercise induces the release of heat shock protein 72 from the human brain in vivo. Cell Stress Chaperones 2004; 9: 276-280.

30. Hightower LE, Guidon PT. Selective release from cultured mammalian cells of heat-shock (stress) proteins that resemble glia-axon transfer proteins. J Cell Physiol 1989; 138: 257-266.

31. Peetz D, Post F, Schinzel H, Schweigert R, Schollmayer C, Steinbach K, Dati F, Noll F, Lackner KJ. Glycogen phosphorylase $\mathrm{BB}$ in acute coronary syndromes. Clin Chem Lab Med 2005; 43: 1351-1358.

32. Krause EG, Rabitzsch G, Noll F, Mair J, Puschendorf B. Glycogen phosphorylase isoenzyme $\mathrm{BB}$ in diagnosis of myocardial ischaemic injury and infarction. Mol Cell Biochem 1996; 160-161: 289-295.

33. Zhing JJ, Cheng JK, Yu M, Li PF. Effects of cross-country running during empty stomach on the serum levels of glucose and fatty acid, glycogen phosphorylseisoenzyme BB and heart-type fatty acid binding protein. J Med Postgrad 2010; 3.

34. Osbakken M, Locko R. Scintigraphy determination of ventricular function and coronary perfusion in longdistance runners. Am Heart J 1984; 108: 296-304.

35. Lozovina M, Đurovic N, Katic R. Position specific morphological characteristics of elite water polo players. CollAntropol 2009; 33: 781-789.

36. Bolli R, Patel BS, Hartley CJ, Thornby JI, Jeroudi MO, Roberts R. Nonuniform transmural recovery of contractile function in stunned myocardium. Am J Physiol 1989; 257: $375-385$.

\section{*Correspondence to}

Snezana Pantovic

University of Montenegro

Krusevac bb

Montenegro 